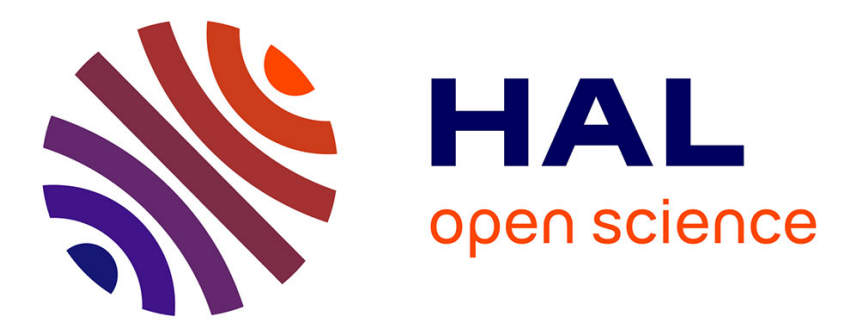

\title{
Mutations that affect coenzyme binding and dimer formation of fungal $17 \beta$-hydroxysteroid dehydrogenase
}

Mojca Brunskole, Katja Kristan, Jure Stojan, Tea Lanišnik Rižner

\section{To cite this version:}

Mojca Brunskole, Katja Kristan, Jure Stojan, Tea Lanišnik Rižner. Mutations that affect coenzyme binding and dimer formation of fungal $17 \beta$-hydroxysteroid dehydrogenase. Molecular and Cellular Endocrinology, 2009, 301 (1-2), pp.47. 10.1016/j.mce.2008.07.023 . hal-00532059

\section{HAL Id: hal-00532059 \\ https://hal.science/hal-00532059}

Submitted on 4 Nov 2010

HAL is a multi-disciplinary open access archive for the deposit and dissemination of scientific research documents, whether they are published or not. The documents may come from teaching and research institutions in France or abroad, or from public or private research centers.
L'archive ouverte pluridisciplinaire HAL, est destinée au dépôt et à la diffusion de documents scientifiques de niveau recherche, publiés ou non, émanant des établissements d'enseignement et de recherche français ou étrangers, des laboratoires publics ou privés. 


\section{Accepted Manuscript}

Title: Mutations that affect coenzyme binding and dimer formation of fungal $17 \beta$-hydroxysteroid dehydrogenase

Authors: Mojca Brunskole, Katja Kristan, Jure Stojan, Tea Lanišnik Rižner

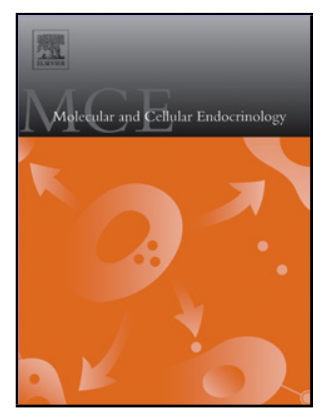

PII:

S0303-7207(08)00337-7

DOI: doi:10.1016/j.mce.2008.07.023

Reference: MCE 6935

To appear in: $\quad$ Molecular and Cellular Endocrinology

Received date: $\quad 30-6-2008$

Revised date: 29-7-2008

Accepted date: $\quad$ 29-7-2008

Please cite this article as: Brunskole, M., Kristan, K., Stojan, J., Rižner, T.L., Mutations that affect coenzyme binding and dimer formation of fungal $17 \beta$ hydroxysteroid dehydrogenase, Molecular and Cellular Endocrinology (2007), doi:10.1016/j.mce.2008.07.023

This is a PDF file of an unedited manuscript that has been accepted for publication. As a service to our customers we are providing this early version of the manuscript. The manuscript will undergo copyediting, typesetting, and review of the resulting proof before it is published in its final form. Please note that during the production process errors may be discovered which could affect the content, and all legal disclaimers that apply to the journal pertain. 
Mutations that affect coenzyme binding and dimer formation of fungal 17 $\beta$-hydroxysteroid dehydrogenase

Mojca Brunskole ${ }^{1}$, Katja Kristan ${ }^{1,2^{*}}$, Jure Stojan ${ }^{1}$, Tea Lanišnik Rižner ${ }^{1}$

${ }^{1}$ Institute of Biochemistry, Faculty of Medicine, University of Ljubljana, Ljubljana, Slovenia

${ }^{2}$ Lek Pharmaceuticals d. d., Drug Discovery, Ljubljana, Slovenia

*Corresponding author: Katja Kristan

University of Ljubljana, Faculty of Medicine, Institute of Biochemistry,

Vrazov trg 2,

1000 Ljubljana, Slovenia

Tel. +386-1-5437652

Fax. +386-1-54376 41

E-mail: katja.kristan@mf.uni-lj.si 
Keywords: $17 \beta$-hydroxysteroid dehydrogenase, site-directed mutagenesis, coenzyme binding, dimerization

\begin{abstract}
:
The $17 \beta$-hydroxysteroid dehydrogenase from the fungus Cochliobolus lunatus (17 $\beta$-HSDcl) is an NADPH-dependent member of the short-chain dehydrogenase/reductase superfamily, and it functions as a dimer that is composed of two identical subunits. By constructing the appropriate mutants, we have examined the M204 residue that is situated in the coenzyme binding pocket, for its role in the binding of the coenzyme $\operatorname{NADP}(\mathrm{H})$. We have also studied the importance of hydrophobic interactions through F124, F132, F133 and F177 for 17 $\beta$-HSDcl dimer formation. The M204G substitution decreased the catalytic efficiency of 17 $\beta$-HSDcl, suggesting that M204 sterically coerces the nicotinamide moiety of the coenzyme into the appropriate position for further hydride transfer. Phenylalanine substitutions introduced at the dimer interface produced inactive aggregates and oligomers with high molecular masses, suggesting that these hydrophobic interactions have important roles in the formation of the active dimer.
\end{abstract}

\title{
1. Introduction
}

Enzymes that belong to the short-chain dehydrogenase/reductase (SDR) superfamily are functionally very heterogeneous and they have low sequence identities (about 15-30\%) (Oppermann et al., 2003). However, they have several distinct sequence motifs in common and display highly similar $\alpha / \beta$ folding patterns with a central $\beta$-sheet, known as the Rossmann fold (Oppermann et al., 2001, Oppermann et al., 2003). The majority of the SDRs act as NAD(P)(H)dependent oxidoreductases and use very diverse substrates (Oppermann et al., 2003).

There are several conserved sequence motifs in the classical SDR family proteins, and two of these form part of the coenzyme binding region. The amino acids from the $\beta 6$-strand $([\mathrm{KR}] \mathrm{x}[\mathrm{NS}] \mathrm{xxxPGx \times xT)}$ are in close contact with the nicotinamide moiety and it has been suggested that they can affect the direction of the reaction. The amino acids from the second motif (TGxxxGxG, $\beta 1$-strand and $\alpha 1$-helix) are situated around the adenosine moiety; these have structural roles in the coenzyme binding region and determine coenzyme specificity (Kallberg et al., 2002).

Most of the SDRs function as dimers and tetramers (Jörnvall et al., 1995), and to date, the only SDR members that are known to function as monomers are porcine testicular carbonyl reductase and human carbonyl reductases 1 and 3 (Ghosh et al., 2001; Miura et al., 2008). A typical SDR tetramer has a 2-2-2 symmetry, with two different interfaces between the subunits. The contacts across the $P$ axis are between subunits 1 and 2 (and between 3 and 4), across the $R$ axis, are between subunits 1 and 3 (and 2 and 4), and across the Q axis, are between subunits 1 and 4 (and 2 and 3) (Andersson et al., 1996). In most dimeric SDRs that have had their structure solved crystallographically, the most extensive contacts are those spanning across the Q-axis of tetrameric SDRs; these involve a pair of helices from each monomer $(\alpha \mathrm{E}$ and $\alpha \mathrm{F})$, thus forming a four-helix bundle (Fig. 1) (Jörnvall et al., 1995). This mode of dimerization is sterically impossible in 3 $\alpha$-HSD/carbonyl reductase, where dimerization takes place via the $\mathrm{P}$-axis and involves the $\alpha \mathrm{G}$-helix and $\beta \mathrm{G}$-strand of each subunit (Grimm et al., 2000; Hoffman et al., 2007). 
The 17ß-hydroxysteroid dehydrogenase from the filamentous fungus Cochliobolus lunatus (17 $\beta$ HSDcl) was the first fungal SDR to be purified and cloned (Lanišnik Rižner et al., 1999). It is an NADPH-preferring enzyme and it preferentially catalyses reversible oxidoreductions of androgens and estrogens at the C17 position (Lanišnik Rižner et al., 2000, Kristan et al., 2003). $17 \beta-H S D c l$ contains all of the typical motifs of the classical SDR family (Lanišnik Rižner et al., 1999). Two threonines (T202 and T200) from the $[\mathrm{KR}] \mathrm{x}[\mathrm{NS}] \mathrm{xxxPGxT}_{(200)} \mathrm{xT}_{(202)}$ motif are in close contact with the nicotinamide moiety, and we have already studied their role for interactions with NADP $(\mathrm{H})$ (Kristan et al., 2003, Kristan et al., 2005a). Here we have studied the role of the neighbouring M204 in the binding of the coenzyme NADP(H) (Fig. 2).

$17 \beta-H S D c l$ is dimer under native conditions (Lanišnik Rižner et al., 1999). Structural model (Lanišnik Rižner et al., 2000) and a recently resolved crystal structure (our unpublished data) identified salt bridges/H-bonds (between R129 and E117/D121, and between H111 and D187) and strong hydrophobic and aromatic interactions (for F120, F124, F132, F133, F177) among the $\alpha \mathrm{E}$ and $\alpha \mathrm{F}$ helices of both of the subunits that can stabilize dimerization (Kristan et al., 2005b). Previously, the roles in dimerization of H111 and R129 were examined (Kristan et al., 2005b), where the H111L, H111A and R129D mutations were constructed, with the aim of selectively disturbing the ionic interactions between monomeric subunits and introducing electrostatic repulsion (R129A). The H111L and R129L mutations both rendered 17 $\beta$-HSDcl monomeric, while the H111A mutant was dimeric. Despite conserved secondary structures, monomers showed no enzymatic activity. In the present study, we have examined the roles of amino acids F124, F132, F133 and F177 (Fig. 1) in dimer formation, and investigated the importance of dimerization for enzymatic activity.

\section{Materials and methods}

2.1. Construction, expression and purification of the mutated proteins

The mutant proteins were prepared using the Quick Change II Site-Directed Mutagenesis Kit (Stratagene) and the pGex-17 $\beta$-HSDcl expression vector. The following primers were used (only forward primers are shown, with the mutations introduced underlined):

M204G: 5'-CGGTACCGTGACAGATGGCTTCCACGAGGTCTCG-3'

F124A: 5'-GAGTTTGACCGCGTCGCGAGCCTCAACACCCG-3'

F132A: 5'-CCCGAGGCCAGGCGTTCGTCGCTCGC-3'

F132/133A: 5'-CCCGAGGCCAGGCGGCGGTCGCTCGCGAGGC -3'

F177A: 5'-GCCGTCGACTCCGCGGTTCGCATTTTCTCAAAGG -3'

All of the proteins were prepared as a glutathione S-transferase (GST)-fusion proteins in BL21AI Escherichia coli cells (Invitrogen) and purified by affinity binding to glutathione-Sepharose, followed by cleavage with thrombin, as described previously (Lanišnik Rižner et al., 1999). The purities of the proteins were checked by SDS-PAGE. Four $\mu \mathrm{g}$ of each sample was denaturated in Laemmli sample buffer $\left(10 \mathrm{~min}, 95^{\circ} \mathrm{C}\right)$, applied onto $12 \%$ polyacrylamide gels and visualized by Coomassie Blue staining. Protein aliquots of approximately $0.05 \mu \mathrm{g}$ were used for Western blotting. Electrophoresis and transfer were performed as described elsewhere. Rat monoclonal antibodies against 17 $\beta$-HSDcl (Kristan et al., 2003) were used as primary antibodies (overnight incubation at $4{ }^{\circ} \mathrm{C}$ ). The secondary antibodies were peroxidase-conjugated goat anti-rat $\operatorname{IgG}+\operatorname{IgM}$ (H+L); Jackson ImmunoResearch Laboratories Inc., West Grove, Pennysylvania, USA), diluted 1:5000 and incubated for 2 hours at $25{ }^{\circ} \mathrm{C}$. Colour was developed using Supersignal West Pico Chemiluminiscence Substrate (Pierce Biotechnology). PAGE under non-denaturing conditions was performed on $9 \%$ acrylamide gels with $5 \mu \mathrm{g}$ protein, as described previously (Kristan et al., 2003). 


\subsection{Determination of enzymatic activities \\ Activity staining}

The screening for activities of the expressed proteins was carried out by activity staining, as described previously (Kristan et al., 2003). Briefly, following PAGE under non-denaturing conditions, the gels were equilibrated in (final concentrations) $50 \mathrm{mM}$ Tris buffer, $\mathrm{pH} 9.0$, with $0.5 \mathrm{mM} \mathrm{NADP}{ }^{+}, 0.5 \mathrm{mM}$ substrate 4-estrene-17 $\beta$-ol-3-one and $1.5 \mathrm{mM} \beta$-cyclodextrine. The activity staining was started by the addition of $0.1 \mathrm{mM}$ phenazine methosulfate and $0.3 \mathrm{mM}$ nitroblue tetrazolium salt (final concentrations). The gels were incubated in the dark at $4{ }^{\circ} \mathrm{C}$ until the colour developed.

Spectrophotometric assay

The reduction of 4-estrene-3,17-dione and oxidation of 4-estrene-17 $\beta$-ol-3-one $(50-100 \mu \mathrm{M})$ in the presence of coenzymes NADPH and $\operatorname{NADP}^{+}(50-100 \mu \mathrm{M})$ by wild-type $17 \beta-\mathrm{HSDcl}$ and its mutants $(0.5 \mu \mathrm{M})$ was followed on a Beckman DU diode array spectrophotometer, equipped with the Peltier thermostability unit. The time-course of change in absorbance at $340 \mathrm{~nm}$ was measured from 7 to $1,000 \mathrm{~s}$. All measurements were carried out in $100 \mathrm{mM}$ phosphate buffer, $\mathrm{pH}$ 8.0 , at $25^{\circ} \mathrm{C}$. The progress curves were analyzed as described previously (Lanišnik Rižner et al., 2000, Kristan et al., 2005a), and the classical kinetic parameters, $K_{M}$ and $k_{\text {cat }}$, were derived for the active proteins (Kristan et al., 2005a).

\section{Results and discussion}

All of the 17ß-HSDcl mutants were prepared by site-directed mutagenesis, overexpressed in $E$. coli, and purified. The purities of the expressed proteins were checked by SDS PAGE, where all of the proteins appeared as bands with the expected molecular mass of $28 \mathrm{kDa}$, and were recognized by anti-17 $\beta$-HSD antibodies (Fig. 3). Their solution molecular masses were determined by non-denaturing PAGE, where differences in mobilities of these proteins were seen (Fig. 4a).

\section{The role of Met204 in the binding of the coenzyme}

In proteins from the SDR superfamily, the coenzyme binds to the enzyme in an extended conformation, with the adenine ring in an anti conformation and the nicotinamide ring in a syn conformation. Amino-acid residues from the C-terminal part of the $\beta 6$-strand are in close contact with the nicotinamide moiety of the coenzyme, and they contribute to the correct accommodation of the nicotinamide moiety (Kallberg et al., 2002; Persson et al., 2003; Shi et al., 2004).

In 17 $\beta$-HSDcl, two threonines (T200, T202) have previously been shown to interact with the nicotinamide of NADPH (Kristan et al., 2003, Kristan et al., 2005a). The M204 is close to the two threonines, and it is conserved across some of the SDR superfamily, although its role has never been defined. M204 can thus be seen in 3 $\alpha, 20 \beta$-HSD from Streptomyces hydrogenans (M189) (PDB code 2HSD) (Ghosh et al., 1994), trihydroxynaphtalene reductase and tetrahydoxynaphtalene reductase from Magnaporthe grisea (M215 and M215) (PDB codes 1 YBV and 1JA9, respectively) (Andreson et al., 1996; Liao et al, 2001), versicolorin reductases from Aspergillus parasiticus (M195) and Emericella nidulans (M197) (EBI Databases), and also in mammalian carbonyl reductases: mouse (M187) (pdb code 1CYD) (Tanaka et al., 1996), pig (M234) (pdb code 1N5D) (Ghosh et al., 2001) and human (M234) (pdb code 1WMA) (Tanaka et al., 2005). The crystal structures have revealed that the corresponding methionine is positioned 
right above the nicotinamide ring, and it probably provides steric force for the correct accommodation of the pyridine nucleotide part of the coenzyme. We substituted M204 of $17 \beta$ HSDcl by glycine and decreased enzyme activity was initially detected by activity staining after native PAGE. Kinetic constants were determined for M204 mutant and then compared to the wild type. The $k_{\text {cat }}$ values for NADPH and $\mathrm{NADP}^{+}$decreased 127 -fold and 35 -fold, and the $K m$ values increased 43-fold and 833-fold, respectively (Table 1). These lower $k_{\text {cat }}$ and increased $K m$ values contribute to a lower specificity constant $k_{\text {cat }} / \mathrm{Km}$ for both cofactors $\left(6 \times 10^{3}\right.$-fold and $2.5 \times 10^{4}$-fold, for NADPH and $\mathrm{NADP}^{+}$, respectively) (Table 1). Bearing in mind that $17 \beta-\mathrm{HSDcl}$ is already a 'bad' enzyme, such further drastic decreases in its catalytic power with the M204G mutant confirms that M204 provides an important contribution in the correct accommodation of the nicotinamide moiety during the enzymatic reaction.

\section{The role of hydrophobic interactions in dimer formation}

We have shown previously that wild-type $17 \beta-H S D c l$ is active as a dimer (Lanišnik Rižner et al., 1999). Examination of the three-dimensional model and crystal structure of fungal 17 $\beta$-HSD (Lanišnik Rižner et al., 2000; our unpublished data) has allowed the identification of salt bridges/ H-bonds (H111, E117, D121, R129, D187) and strong hydrophobic and aromatic interactions (F120, F124, F132, F133, F177) across the Q-axis. To prevent dimerization of 17ß-HSDcl, several mutants were prepared that were expected to weaken the hydrophobic interactions (F124A, F132A, F132/133A and F177A).

To our surprise, all of the phenylalanine substitutions resulted in inactive oligomers and aggregates (Fig. 4). Even a single phenylalanine substitution prevented the formation of the correct dimer. Presumably the surface of those $17 \beta$-HSDcl mutants was too hydrophobic to remain exposed to the solvent and (random) packing of the monomers occurred. Similar effects were also seen in dimeric human 17 $\beta$-HSD type 1 (Puranen et al., 1997) and Drosophila alcohol dehydrogenase (Chenevert et al., 1995). The mutated proteins (L111E/V113F and A170E+F172 for 17 $\beta$ HSD1 and A159T for alcohol dehydrogenase) formed inactive aggregates.

To determine how important the masking of the $\alpha \mathrm{E}$ and $\alpha \mathrm{F}$ helices is for enzyme activity, we compared the structures of monomeric carbonyl reductases (Ghosh et al., 2001; Miura et al., 2008). These are indeed monomeric, but they all have a predominantly $\alpha$-helical subdomain that covers and stabilizes the two helices. However, the prevention of the native conformation also resulted in a loss of the enzyme activity. This can be explained by the stability of the $\alpha \mathrm{E}$ and $\alpha \mathrm{F}$ helices and the correct orientation of the catalytic residues Y167 and K171 of the interior side of the $\alpha \mathrm{F}$ helix. Another SDR member, glucose dehydrogenase from Bacillus megaterium IWG3, functions as a tetramer, although it reversibly dissociates into inactive monomers at high $\mathrm{pH}$, due to weaker hydrophobic interactions and a lack of salt bridges in the Q-interface (Yamamoto et al., 2001). Those results thus demonstrate that only upon dimerization the key catalytic residues are brought into the positions that allow the substrate conversion. Additionally, it has been described that the enzyme may undergo conformational changes during the catalysis, and for this the stability of these two helices might be important (Ratnam et al., 1999; Ueda et al., 2004).

\section{Conclusions}

Using site-directed mutagenesis, we have investigated M204 of 17 $\beta$-HSDcl, which is situated in the coenzyme-binding pocket, for its role in the binding of the coenzyme NADP $(H)$, and the 
importance of hydrophobic interactions (involving F124, F132, F133 and F177 residues) for dimer formation. The substitution of M204 with G decreased the catalytic efficiency and indicates that M204 provides steric coercion to the nicotinamide moiety of the coenzyme for it to take up the appropriate position for further hydride transfer. Phenylalanine substitutions introduced at the dimer interface resulted in inactive oligomers with high molecular masses. The site-specific substitutions introduced and structure/function analysis indicate the importance of hydrophobic interactions in the native $17 \beta$-HSDcl conformations. 


\section{Acknowledgements}

This work was supported by a P1 -170 research grant and a young researcher grant to M.B., both from the Slovenian Research Agency. The authors thank to Dr. Chris Berrie for critical reading of the manuscript. 


\section{References}

Andersson, A., Jordan, D., Schneider, G., Lindqvist, Y., 1996. Crystal structure of the ternary complex of 1,3,8-trihydroxynaphthalene reductase from Magnaporthe grisea with NADPH and an active-site inhibitor. Structure 4, 1161-1170.

Chenevert, S.W., Fossett, N.G., Chang, S.H., Tsigelny, I., Baker, M.E., Lee, W.R., 1995. Amino acids important in enzyme activity and dimer stability for Drosophila alcohol dehydrogenase. Biochem. J. 308, 419-423.

EBI Databases, Protein Databases, CluSTr Database: http://www.ebi.ac.uk/Databases (June 2008)

Ghosh, D., Sawicki, M., Pletnev, V., Erman, M., Ohno, S., Nakajin, S., Duax, W.L., 2001. Porcine carbonyl reductase. J. Biol. Chem. 276, 18457-18463.

Ghosh, D., Wawrzak, Z., Weeks, C.M., Duax, W.L., Erman, M., 1994. The refined threedimensional structure of 3 alpha, 20 beta-hydroxysteroid dehydrogenase and possible roles of the residues conserved in short-chain dehydrogenases. Structure 2, 629-640.

Grimm, C., Maser, E., Möbus, E., Klebe, G., Reuter, K., Ficner, R., 2000. The crystal structure of 3alpha-hydroxysteroid dehydrogenase/carbonyl reductase from Comamonas testosteroni shows a novel oligomerization pattern within the short chain dehydrogenase/reductase family. J. Biol. Chem. 275, 41333-41339.

Hoffman, F., Sotriffer, C., Evers, A., Xiong, G., Maser, E., 2007. Understanding oligomerization in 3alpha-hydroxysteroid dehydrogenase/carbonyl reductase from Comamonas testosteroni: an in silico approach and evidence for an active protein. J. Biotechnol. 129, 131-139.

Jörnvall, H., Persson, B., Krook, M., Atrian, S., Gonzalez-Duarte, R., Jeffery, J., Ghosh, D., 1995. Short-chain dehydrogenases/reductases (SDR). Biochemistry 34, 6003-6013.

Kallberg, Y., Oppermann, U., Jornvall, H.,Persson, B., 2002. Short-chain dehydrogenases/reductases (SDRs). Eur. J. Biochem. 269, 4409-4417.

Kristan, K., Deluca, D., Adamski, J., Stojan, J., Lanišnik Rižner, T., 2005b. Dimerization and enzymatic activity of fungal 17beta-hydroxysteroid dehydrogenase from the short-chain dehydrogenase/reductase superfamily. BMC Biochem. 6, 28.

Kristan, K., Lanišnik Rižner, T., Stojan, J., Gerber, J.K., Kremmer, E., Adamski, J., 2003. Significance of individual amino acid residues for coenzyme and substrate specificity of $17 \beta$-hydroxysteroid dehydrogenase from the fungus Cochliobolus lunatus. Chem. Biol. Interact. 143-144, 493-501.

Kristan, K., Stojan, J., Möller, G., Adamski, J., Lanišnik Rižner, T., 2005a. Coenzyme specificity in fungal 17beta-hydroxysteroid dehydrogenase. Mol. Cell. Endocrinol. 241, 80-87.

Lanišnik Rižner, T., Moeller, G., Thole, H.H., Žakelj-Mavrič, M., Adamski, J., 1999. A novel $17 \beta$-hydroxysteroid dehydrogenase in the fungus Cochliobolus lunatus: new insights into the evolution of steroid-hormone signalling. Biochem. J. 337, 425-431.

Lanišnik Rižner, T., Adamski, J., Stojan, J., 2000. 17 $\beta$-hydroxysteroid dehydrogenase from Cochliobolus lunatus: Model structure and substrate specificity. Arch. Biochem. Biophys. 382, 255-262.

Liao, D.I., Thompson, J.E., Fahnestock, S., Valent, B., Jordan, D.B., 2001. A structural account of substrate and inhibitor specificity differences between two naphthol reductases. Biochemistry 40, 8696-8704.

Miura, T., Nishinaka, T., Terada, T., 2008. Different functions between human monomeric carbonyl reductase 3 and carbonyl reductase 1. Mol. Cell. Biochem. In press. 
Opperman, C.T.U., Filling, C., Jörnvall, H., 2001. Forms and functions of human SDR enzymes. Chem. Biol. Interact. 130-132, 699-705.

Oppermann, C.T.U., Filling, C., Hult, M., Shafqat, N., Wu, X., Lindh, M., Shafqat, J., Nordling,

E., Kallberg, Y., Persson, B., Jörnvall, H., 2003. Short-chain dehydrogenases/reductases

(SDR): the 2002 update. Chem. Biol. Interact. 143-144, 247-253.

Persson, B., Kallberg, Y., Oppermann, C.T.U., Jörnvall, H., 2003. Coenzyme-based functional assignments of short-chain dehydrogenases/reductases (SDRs). Chem. Biol. Interact. 143144, 271-278.

Puranen, T., Poutanen, M., Ghosh, D., Vihko, P., Vihko, R., 1997. Characterization of structural and functional properties of human 17 $\beta$-hydroxysteroid dehydrogenase type 1 using recombinant enzymes and site-directed mutagenesis. Mol. Endocrinol. 11, 77-86.

Ratnam, K., Ma, H., Penning, T.M., 1999. The arginine 276 anchor for NADP(H) dictates

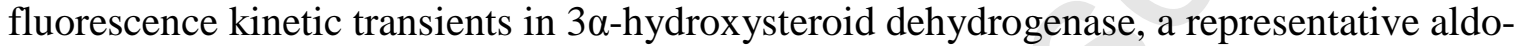
keto reductase. Biochemistry 38, 7856-7864.

Shi, R., Lin, S.X., 2004. Cofactor hydrogen bonding onto the protein main chain is conserved in the short chain dehydrogenase/reductase family and contributes to nicotinamide orientation. J. Biol. Chem. 279, 16778-16785.

Tanaka, M., Bateman, R., Rauh, D., Vaisberg, E., Ramachandani, S., Zhang, C., Hansen, K.C., Burlingame, A.L., Trautman, J. K., Shokat, K. M., Adams, C. L., 2005. An unbiased cell morphology-screen for new, biologically active small moleculec. PLoS Biol. 3, 128.

Tanaka, N., Nonaka, T., Nakanishi, M., Deyashiki, Y., Hara, A., Mitsui, Y., 1996. Crystal structure of the ternary complex of mouse lung carbonyl reductase at $1.8 \AA$ resolution: the structural origin of coenzyme specificity in the short-chain dehydrogenase/reductase family. Structure 4, 33-45.

Ueda, S., Oda, M., Imamura, S., Ohnishi, M., 2004. Transient-phase kinetic studies on the nucleotide binding to $3 \alpha$-hydroxysteroid dehydrogenase from Pseudomonas sp. B-0831 using fluorescence stopped-flow procedures. Eur. J. Biochem. 271, 1774-1780.

Yamamoto, K., Kurisu, G., Kusunoki, M., Tabata, S., Urabe, I., Osaki, S., 2001. Crystal structure of glucose dehydrogenase from Bacillus megaterium IWG3 at $1.7 \AA$ resolution. J. Biochem. (Tokyo) 129, 303-312. 


\section{Figure legends}

Figure 1. Ribbon diagram showing the dimerization of $17 \beta-\mathrm{HSDcl}$ across the Q-axis (left) and the amino acids involved in the dimerization that were exchanged by site-directed mutagenesis (right).

Figure 2. Part of the homology model structure with bound coenzyme NADPH and substrate androstenedione, showing the residues that are important for coenzyme binding: T200 and T202, as well as M204, which was replaced with glycine.

Figure 3. Western blot of wild-type 17ß-HSDcl and the F124A, F132A, F132/133A, F177A and M204G mutants. Analysis was performed using monoclonal rat antibodies against recombinant $17 \beta-H S D c l$ and visualized with goat anti-rat IgG-horseradish peroxidase conjugate.

Figure 4. A) Native PAGE. Wild-type 17ß-HSDcl and the F124A, F132A, F132/133A, F177A and M204G mutants were applied to native PAGE gels and stained with Coomassie Blue. B)

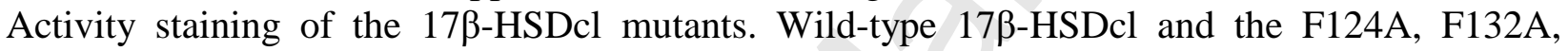
F132/133A, F177A and M204G mutants were applied to native PAGE (as indicated). Activity staining was performed with nitroblue tetrazolium and phenazine methasulfate in the presence of 4-estrene-17ß-ol-3-one and NADP ${ }^{+}$. 


\section{Table 1}

Kinetic constants $\left(K_{m}[\mu \mathrm{M}], k_{c a t}\left[\mathrm{~s}^{-1}\right], k_{\text {cat }} / K_{m}\left[\mathrm{~s}^{-1} \mu \mathrm{M}^{-1}\right]\right)$ for the wild type $17 \beta$-hydroxysteroid dehydrogenase from C. lunatus and M204G mutant with the coenzymes NADPH and $\mathrm{NADP}^{+}$at $\mathrm{pH} 8$ and $25^{\circ} \mathrm{C}$.

\begin{tabular}{lllllll}
\hline & $K_{m}{ }^{N A D P H}$ & $K_{m}{ }^{N A D P+}$ & $k_{\text {cat }}{ }^{N A D P H}$ & $k_{\text {cat }}{ }^{N A D P+}$ & $k_{\text {cat }} / K_{m}{ }^{N A D P H}$ & $k_{\text {cat }} / K_{m}{ }^{N A D P+}$ \\
\hline Wild type & 6.5 & 0.09 & 3.8 & 0.7 & $5.9 \times 10^{5}$ & $7.3 \times 10^{6}$ \\
M204G & 280 & 75 & 0.03 & 0.02 & 106 & 289 \\
\hline
\end{tabular}



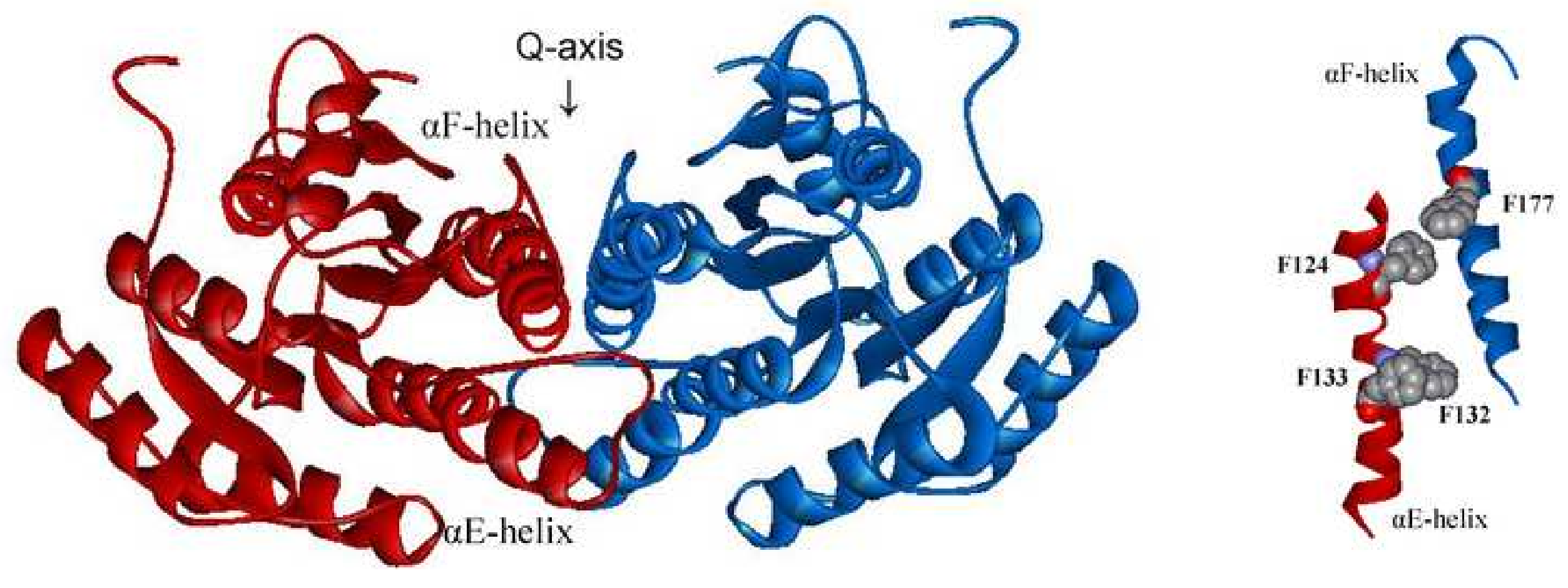


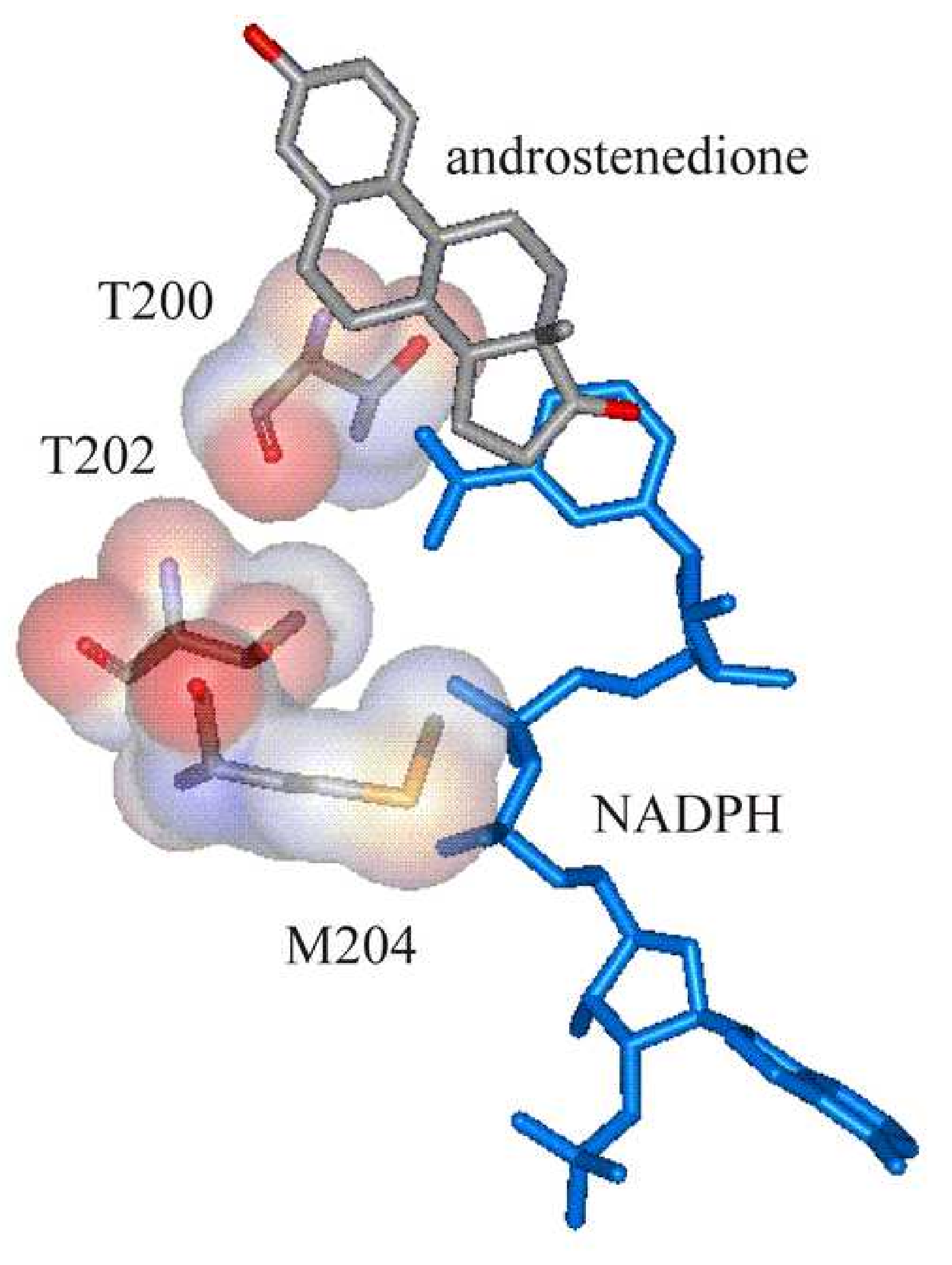

Page 13 of 15

androstenedione

NADPH

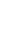

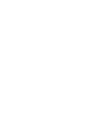




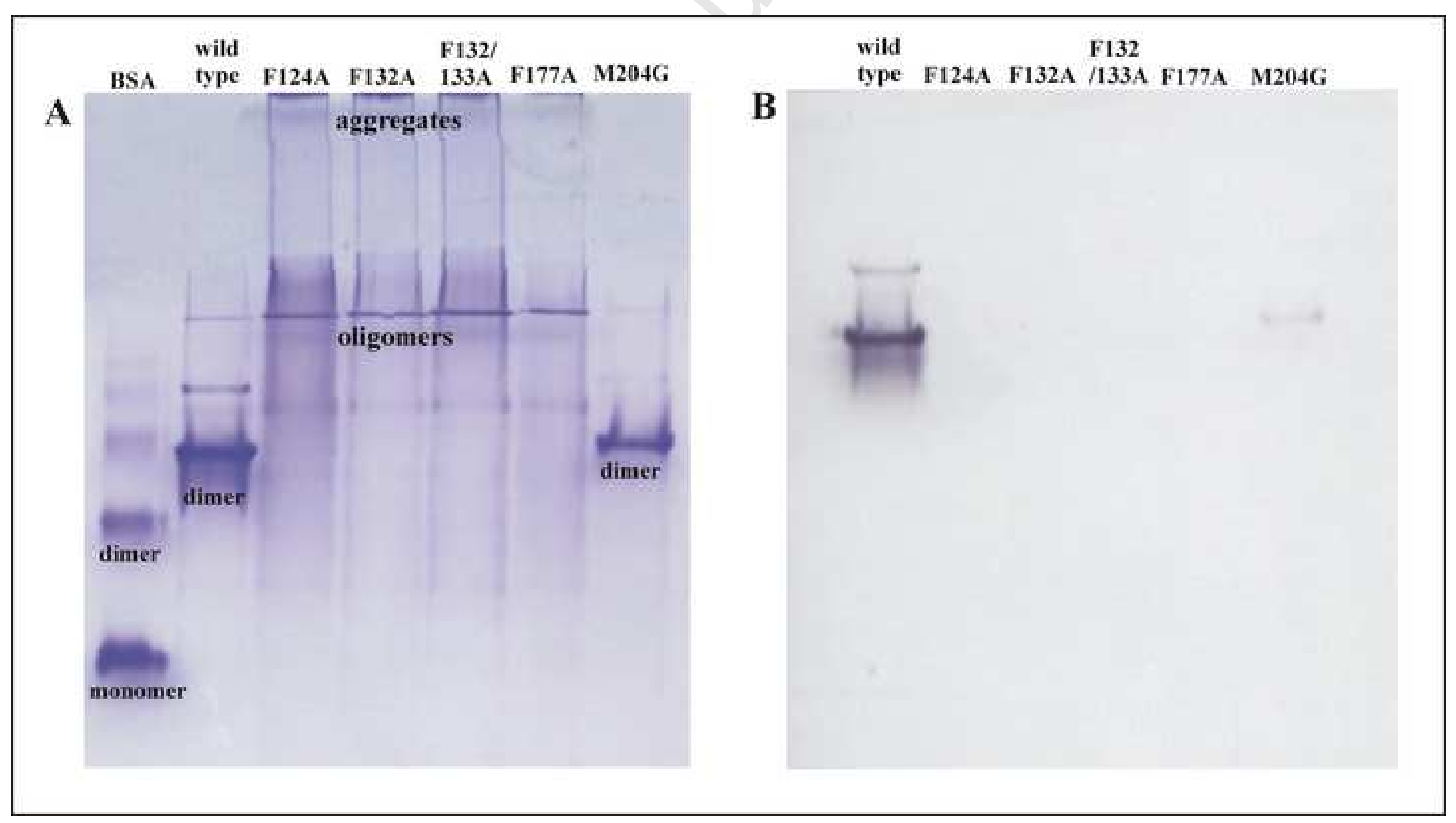

